\title{
APROXIMACIÓN TEÓRICA A LAS INTERRELACIONES ENTRE TURISMO, TRABAJO Y MIGRACIONES INTERNACIONALES EN EL CONTEXTO EUROPEO
}

\author{
Raúl LARDIÉS BOSQUE
}

Becario de Investigación en el Department of Geography del King's College London Strand, LONDON WC2R 2LS

\begin{abstract}
Resumen: En este artículo se analiza la transnacionalización del mercado de trabajo en la industria del turismo a través de las conexiones entre la industria y las migraciones internacionales. Dada la importancia de las tendencias hacia la globalización y el modo en que estas condicionan el impacto del turismo en determinadas regiones de Europa, nos ocupamos de las migraciones internaciones de trabajo dentro de Europa prestando particular atención a los cambios habidos en ellas durante la etapa post-Fordista y en las dos últimas décadas. En segundo lugar prestaremos atención al turismo como gran fuente de puestos de trabajo para los inmigrantes con la importancia que tiene el mercado informal (o economía negra). Finalmente, la tercera parte examina el impacto de la migración internacional de retorno en el desarrollo del turismo en los países de origen de los inmigrantes. En este caso, la información de base es imperfecta y se centra en el examen de casos concretos.
\end{abstract}

Palabras clave: Turismo, empleo, migraciones internacionales, inmigrantes.

\begin{abstract}
This paper addresses the issue of transnationalisation of the labour market in the tourism industry through the links between the industry and international migration. Given the importance of globalisation tendencies and the way that these mediate the impact of tourism on particular regions of Europe, we focus on the international labour migration into Europe paying particular attention to their changing character during the post-Fordist era of the last two decades. Secondly, it will point out the tourism as a major source of jobs for immigrants with the importance of the informal labour market (black economy). Finally, the third part examines the impact of international return migration on the development of tourism in the home countries of the migrants. In this case, the information base is imperfect and the stress is on case-studies.
\end{abstract}

Key words: Tourism, employment, international migrations, immigrants. 


\section{INTRODUCCION}

En este artículo nos proponemos examinar la internacionalización del mercado de trabajo y la mano de obra en la industria del turismo, a través de las conexiones existentes entre esta industria y las migraciones internacionales. Para ello lo dividiremos en tres partes. En la primera haremos referencia a los principales flujos de mano de obra internacional que se dan en Europa, prestando particular atención a los cambios producidos en la era post-fordista de los ultimos veinte años. En segundo lugar nos detendremos en la industria turística como gran fuente de empleos para los inmigrantes; sin embargo, a pesar de que este hecho es bien conocido, existen escasísimos datos para su análisis. Si ya de por sí los datos sobre población inmigrante trabajando por ramas de actividad son escasos, esa ausencia es todavía más llamativa debido a lo "informal" de esta economía. Ello deriva a que muchas veces no haya ninguna constancia de la presencia de esos inmigrantes en el mundo laboral. Por lo tanto, esa ausencia de información cuantitativa tiene que ser suplida en ocasiones por una descripción más cualitativa de los papeles y las funciones que estos inmigrantes desempeñan en la industria del turismo.

La tercera parte, y final, examina el impacto de las migraciones de retorno en el sector turístico de los países de origen de los emigrantes. También, en este caso, la información es escasa e incompleta, y está ceñida a los estudios de casos concretos realizados, la mayoría de ellos en países mediterráneos.

\section{LAS NUEVAS MIGRACIONES INTERNACIONALES EN EL CONTEXTO EUROPEO}

\section{Migraciones masivas en la etapa industrial}

Hace mucho tiempo de las masivas migraciones de trabajo que se dieron en los años 50 y 60 desde los países del Sur de Europa hacia los del centro y del Norte. Vistas en retrospectiva, su explicación casa con una visión demográfica del fordismo, en e1 sentido de que se produjeron desde las regiones periféricas europeas con abundante mano de obra barata hacia las que entraban en su etapa industrial y de producción masiva tras la postguerra (FIELDING, 1993). Millones de trabajadores emigraron a grandes ciudades y zonas industriales del Norte y Oeste de Europa desde países tales como España, Portugal, Italia, Grecia o Irlanda, estando algunos de esos flujos muy canalizados desde países como Argelia a Francia, de Turquía a Alemania occidental, o desde Marruecos a Bélgica y Holanda; de la misma manera que grandes contingentes se dirigieron desde las colonias o ex-colonias en Africa, Sureste asiático y Caribe hacia las potencias imperialistas occidentales. 
Mucho se ha escrito sobre estas migraciones, atribuyendo al capitalismo europeo la gran demanda de esa mano de obra barata (CASTLES \& KOSACK, 1973). Las tesis marxistas defendidas por Castles y Kosack y otros autores como PIORE (1979) o COHEN (1987) se referían a estos migrantes por lo general como mano de obra industrial, aunque es importante puntualizar que en ese momento previo a la crisis petrolífera del 73 muchos de ellos se dirigieron a puestos en las actividades de los servicios, ${ }^{1}$ continuando muchos todavía hoy con sus negocios en esos países (Bélgica, Francia, Alemania, etc.), como en el caso de pequeños propietarios de tiendas y restaurantes (muchas veces concentrados respondiendo a determinados grupos étnicos).

En el caso concreto del Reino Unido, ese agrupamiento y concentración de determinada población extranjera en determinados sectores y tipos de establecimientos relacionados con la industria turística (alimentación fundamentalmente) es bien conocido: restaurantes y take-away chinos e indios, Fish and Chips chipriotas, pizzerías italianas, etc. $Y$ aunque muchos de ellos también existen en otros países, esas concentraciones étnicas reflejan perfectamente las áreas de emigración como el Norte de Africa en Francia, Turquía en Alemania, o Indonesia en Holanda. Sin embargo, no todas estas industrias de inmigrantes tienen su origen en la etapa fordista de las décadas de la postguerra, sino que muchas de ellas son bastante más recientes. ${ }^{2}$

\section{El nuevo contexto de las Migraciones internacionales europeas}

Tras los acontecimientos de la crisis petrolífera de la década de los 70 y con 1 a llegada de la década de los 80 , se empezaron a producir cambios importantes en las migraciones europeas ante el nuevo contexto de la internacionalización y globalización del mercado de trabajo.

\footnotetext{
1 Es el caso, por ejemplo, de los trabajadores procedentes del Caribe y con destino en el Reino Unido, ocupados en el sector sanitario (hospitales) y en el transporte británicos.

2 En el Reino Unido, por ejemplo, la industria desarrollada tanto en las ramas de la hostelería como de la hotelería es bastante vieja y su origen responde a la llegada inicial de vendedores de helados a finales del pasado siglo. Hoy esta industria italiana controla buena parte de esas ramas ofreciendo una gran variedad de servicios a lo largo de todo el país: vendedores de helados en camionetas y tiendas, snack-bars, Coffee-shops, pizzerías, restaurantes, hoteles, etc. Hay que decir que muchas firmas del sector son llevadas hoy en día por personal italiano, como los famosos bares Costa Coffee, habituales en aeropuertos y estaciones de trenes. $O$ también, no es nada anormal que los propietarios de un Restaurante-Pub inglés sean una familia italiana, si no de primera, de segunda o tercera generación de inmigrantes.

Algunos de esos italianos han llegado hasta lo más alto con sus negocios, como Lord Charles Forte, hoy dueño de uno de los más grandes imperios hoteleros y de restauración de Europa. Forte nació en un pequeño pueblo del sur de Italia y emigró a Escocia siendo un muchacho para unirse a su familią que ya estaba allí trabajando en la venta de helados y cafés italianos (FORTE, 1986). De la misma forma, el grupo de hostelería Berni tuvo unos orígenes similares, pero en este caso con negocios originariamente en el sur de Gales (HUGHES, 1991).
} 
Uno de los temas que más ha atraído la atención de los estudiosos ha sido el impacto de la globalización y de la mundialización de la económica en la organización de la producción y, en consecuencia, la influencia que ello ha tenido en los nuevos desplazamientos de población en el seno europeo y desde fuera de la Unión Europea hacia algunos países que la componen. En ese sentido, es interesante no olvidar lo que ha supuesto y está suponiendo la restructuración de la economía, porque allí está la clave de la nueva organización del modo de produccción en el sector turístico y de los flujos que se producen en relación con el empleo en dicho sector.

El proceso general de cambio económico, social y cultural que se ha dado a todos los niveles, no sólo a escala europea sino también mundial, está ligado a una nueva organización espacial de la producción y del consumo. Desde el punto de vista geográfico, este proceso ha implicado profundas transformaciones en la geografía de la producción y del consumo afectando fuertemente a gran número de regiones en Europa, tanto en las zonas "centro" como en las "periféricas" (DICKEN, 1992; COOKE, 1989). Por tanto, si las transformaciones económicas han generado una serie de cambios en la dinámica de la población afectando fuertemente a algunas regiones europeas, a su vez, esos movimientos de población han tenido su influencia también en la restructuración económica. Es el caso por ejemplo de las migraciones internacionales de los años 50 y 60 que ayudaron al sostenimiento de los procesos ligados al mercado de trabajo asociados en etapa de producción Fordista, o el caso hoy en día del turismo en el Mediterráneo (planteado desde el punto de vista de una actividad económica afectada por los nuevos procesos de restructuración económica); en cualquier caso, se trata de un conjunto de procesos que, directa o indirectamente, están ligados con la movilidad de la población en el área (MONTANARI, 1995).

En este momento, los países del Sur de Europa que habían exportado mano de obra durante décadas se convirtieron en países receptores de inmigrantes, principalmente venidos desde otros países de la zona mediterranea (MONTANARI \& CORTESE, 1993). En esta nueva "era de las migraciones" (CASTLES \& MILLER, 1993) las ligazones y las interdependencias entre diferentes partes del mundo están tan extendidas y son tan grandes que las migraciones se pueden producir sin ningún tipo de lazos culturales, geográficos o coloniales entre los países emisores y receptores, y sin que haya fuertes demandas de mano de obra desde los países receptores. Así, el peso de los factores no económicos, tales como los sociales, demográficos o políticos en determinadas migraciones, ha aumentado, favorecido por la facilidad y el intercambio de información entre zonas muy distantes de la "aldea global" (GOLINI et al., 1993).

Autores como CASTLES \& MILLER (1993) y SALT et al. (1994) han estudiado las dimensiones de las nuevas corrientes migratorias en las décadas de los 80 y de los 90 en el contexto de la nueva restructuración económica y política, analizando los 
cambios en los orígenes, mecanismos y tipos de estas migraciones. En tal proceso de cambio económico y del mercado de trabajo, el cambio global del modelo de inversiones ha hecho que muchas industrias hayan desplazado sus plantas de producción al "Tercer Mundo" donde la mano de obra es mucho más barata y flexible. La revolución electrónica, que ha hecho disminuir la demanda de trabajadores manuales en los procesos de producción, ha hecho variar la tradicional demanda de trabajadores del sector industrial, así como el origen de esas migraciones tradicionales. Mientras que el mercado de trabajo europeo ha tenido una rápida expansión en el sector servicios especialmente promovido por el turismo-, también es cierto que han aumentado las prácticas de economía "negra" o "informal". De forma que por lo que respecta al mercado de trabajo y a la demanda de trabajadores, eso se ha traducido en la mayor inseguridad de las condiciones de trabajo, y el incremento del mismo a tiempo parcial o estacional. Lo cual, por otro lado, significa una mayor diferenciación de los trabajadores en cuanto a sexo, edad $u$ origen geográfico: muchas mujeres en determinadas ramas de la economía, inmigrantes trabajadores jóvenes, y la mayoría de las veces insuficientemente pagados. Muy frecuentemente esta segmentación del mercado de trabajo es encontrada en el sector turístico, tanto en las grandes ciudades como en destinos turísticos masivos.

La situación de inseguridad de muchos de estos miembros de la economía "informal" o también "secundaria" del mercado de trabajo se ve reforzada por su posición precaria de inmigrantes ilegales. Inmigrantes de países menos desarrollados o del antiguo bloque de Europa oriental residen de forma clandestina al haber entrado con visas turísticas para pocos días, pero tras encontrar algún trabajo para sobrevivir en estos países, se quedan a residir en ellos una vez agotados los plazos legales de esas visas. Esto se ha producido por lo general en los países de la cuenca mediterránea, donde los controles de inmigración son menos severos, donde los puntos de entrada se multiplican debido a los muchos kilómetros de líneas de costa, y donde bajo la masiva entrada de turistas se enmascaran cientos de inmigrantes con intenciones de encontrar un empleo y quedarse a residir en alguno de estos países. Por eso, a continuación nos centraremos en una rápida revisión del caracter turístico de los trabajadores inmigrantes en países como Italia o España.

A pesar de los crecientes controles de inmigración que desde hace pocas décadas se están imponiendo los países de la Unión Europea, el número de trabajadores inmigrantes en Europa occidental ha aumentado rápidamente en las décadas de los años 80 y 90. Las razones de esta aparente contradicción son complejas, pero existen algunos elementos de juicio como la creciente presión de la inmigración proveniente de regiones más pobres, el rápido incremento demográfico, la inestabilidad política, la degradación medioambiental, etc., y el incremento de inmigrantes cualificados que están llegando a Europa. En la década de 1980 a 1990 el total de mano de obra extranjera creció alrededor de la mitad en países como Luxemburgo, un tercio en 
Austria, Suiza y el Reino Unido, un 10\% en Suecia, alrededor del 6-7\% en Francia y Holanda, y un 3\% en Bélgica. Sólo Alemania occidental, tradicionalmente el país de mayor inmigración en Europa, sufrió un declive de un 4\%, aunque el número total de población extranjera creció un 18\% durante esos 10 años (SOPEMI, 1992). Todas estas cifras incluyen datos de trabajadores admitidos (oficiales) y excluye a varias categorías como los temporales o estacionales, solicitantes de asilo, o inmigrantes ilegales; no obstante, las estadísticas varian bastante de unos países a otros.

Lo que es más importante de apreciar es la variedad de mecanismos de migración a Europa (SALT et al., 1994), de los cuales buen número de ellos los ponen en práctica los solicitantes de asilo cuyo número ha crecido rápidamente desde mediados de la década de los 80. Muchos entran ilegalmente en el país mientras su solicitud de asilo está siendo tramitada y se quedan trabajando ilegalmente en el país si esa solicitud es denegada. Otro tipo muy común de movilidad es la llevada a cabo por estudiantes en busca de trabajo. Muchos estudiantes aprovechan sus vacaciones para viajar al extranjero y trabajar en sus vacaciones, por lo que reúnen tanto la condición de turistas, como de trabajadores, generalmente en la industria del turismo, y a tiempo parcial.

En países de Europa del Este el fenómeno del "trabajo turístico" se ha convertido en un fenómeno bastante común, sobre todo en zonas limítrofes entre países, donde es fácil atravesar fronteras para trabajar temporalmente en algún otro país. Además de la experiencia de liberdad, los estudiantes consiguen un dinero que les servirá para mantenerse ellos mismos, o para financiarse los estudios cuando regresen a sus países de origen.

Todos estos cambios en el carácter de las migraciones están en relación con los cambios acontecidos en los requerimientos de mano de obra en la industria del turismo. Por ello, el empleo en el sector turístico tiene que estudiarse y verse en el contexto de estas nuevas formas de migración internacional dentro y hacia Europa.

\section{TRABAJADORES INMIGRANTES EN LA INDUSTRIA DEL TURISMO}

\section{E1 Turismo como generador de empleo}

Desde principios de la década de los 90 la industria del turismo y de los viajes en Europa ha sufrido grandes transformaciones. Sin entrar ahora en el análisis de las causas, el desarrollo de una determinada normativa aplicable para todos los estados miembros y la mejora de la industria turística desde el punto de vista de la oferta, lo han convertido en uno de los sectores más competitivos y que mayor número de personas 
emplea no solamente en los países tradicionalmente turísticos como España, Italia o Grecia, sino también en Alemania, Francia o el Reino Unido con la reciente generalización del turismo urbano; en casi todos ellos, el número de empleos ha ido crecimento muy por delante del de otros sectores de la economía.

En relación con las estadísticas publicadas por la OCDE, la creación de un trabajo en industria requiere una inversión siete veces mayor que crearlo en el turismo. De ahí que con una misma inversión es posible crear un número siete veces mayor de trabajos que en industria. Pese a la dificultad para evaluar el empleo generado por las actividades turísticas, se estima que en la Europa comunitaria de la década de los años 80 había 7,5 millones de puestos de trabajo relacionados con el turismo, lo que suponía el $6,5 \%$ del total de los empleos (LOWYCK \& WANHILL, 1992). A principios de la década de los 90 eran unos 35 millones los puestos de trabajo creados por él, lo que representaba aproximadamente un $8,5 \%$ de toda la población empleada (HOLLOWAY, 1993). Estas cifras hablan por sí solas como uno de los sectores en los que el empleo más rápidamente ha crecido en el conjunto de todos los países europeos.

Sin embargo, intentando ser objetivos, se puede decir que no hay cifras exactas referidas al número concreto de trabajadores (tanto directos como indirectos) ocupados en el sector turístico, debido a la gran variedad de métodos para llevar a cabo el recuento. SESSA (1983), por ejemplo, presta atención a 10 categorías de actividades que derivan directamente del turismo: la creación y el mantenimiento de equipamientos y servicios, la producción y la transformación de productos agrarios, el transporte, los servicios comerciales, la construcción de equipamientos de recepción de turistas y determinadas partes de la administración pública. De todas ellas, opina que sólo es posible obtener información sobre el número de empleos ligados directamente a 1 turismo de las tres últimas de ellas.

Se echa en falta, por tanto, un aparato actualizado de estadísticas y datos, con el fin de llevar a cabo una evaluación de los efectos de la creación de empleos por el turismo. Según la Organización Mundial del Turismo (WTO, 1986) existen tres ramas fundamentales en el empleo del sector turístico:

a) La rama más tradicional y obvia del empleo asociada al turismo es la que tiene que ver con los hoteles y los alojamientos (hostales, apartamentos, campings, etc.), y con los restaurantes. Tales establecimientos o empresas son considerados como "turísticos" si la mitad o más de su producción y de los consumidores son turistas o personas que viajan.

b) La segunda rama del empleo que se puede asociar al turismo es la del transporte de pasajeros, considerándose los trabajadores del sector como parte de la fuerza de trabajo turística. 
c) En tercer lugar, otra rama conectada con el turismo es la de las agencias de viajes, en relación con la distribución y marketing del producto turístico tour-operadores, guías, etc.-. En esta categoría también se incluyen los empleados responsables de la organización del tiempo libre y de las actividades de recreo para los turistas.

Sin embargo, además de estas tres categorías, existe un gran número de actividades y empleos auxiliares relacionados con la oferta y el mantenimiento de muchos servicios, que también repercuten favorablemente en la creación de empleos.

\section{Características del empleo turístico y los inmigrantes en el sector}

La cuestión es ver ahora, cómo, y en qué medida, este conjunto de actividades y de empleos, son más o menos atractivos a los inmigrantes. Lo primero que se debe decir es que el turismo, visto desde el punto de vista de la creación de empleos, es una gran empresa internacional que mueve gran número de trabajadores de unas partes del mundo a otras, movimientos que se dan a varios niveles dependiendo de la jerarquía de la empresa turística. Ello implica flujos de personal directivo cualificado, agentes y personal de marketing relacionado con los paquetes turísticos de vacaciones; también representantes de agencias y guías, generalmente mujeres con un nivel educativo medio-alto, facilidad para hablar dos o más idiomas, y gran propensión a la movilidad física. Esto supone que las compañías llevan a cabo inversiones limitadas de capital en puntos concretos, e intentan adaptarse a los cambios del mercado con la movilidad tanto de ese capital como del personal de unos lugares a otros. Dicha movilidad también refleja las características de estacionalidad de esa mano de obra: en los meses de invierno en Canarias o el Caribe, en verano en las Baleares o en las costas mediterráneas españolas, italianas o griegas.

Finalmente, referiéndonos a la base de esa jerarquía de empleos en la industria del turismo hay que decir que el turismo es una industria que demanda una gran flexibilidad de su mano de obra, tanto si se habla de grandes firmas hoteleras que controlan grandes productos turísticos, como en el caso de pequeñas empresas de alojamiento u otros servicios.

La polarización tanto espacial como temporal de la demanda de servicios turísticos ha traído consigo diversos cambios en las firmas del sector, teniendo que adaptarse al mercado, adopción tanto de la flexibilidad numérica (trabajos estacionales y a tiempo parcial, ocasionales, etc.) como de la flexibilidad funcional, con el desempeño por parte de los empleados de diferentes tipos de trabajo (SHAW \& WILLIAMS, 1994). 
Una de las principales características de la mano de obra del sector turístico en todos los países europeos es la estacionalidad de la misma; sobre el 50\% del empleo en hoteles tanto en España como en Grecia es estacional, porcentaje que crece hasta el 80$85 \%$ en zonas concretas como la Costa del Sol o las Islas Baleares, donde en los meses de verano se concentra la gran demanda anual de los turistas del Norte de Europa (VALENZUELA, 1988).

La demanda de trabajo estacional en el sector turístico está muy relacionada, por otra parte, con los deseos de muchos emigrantes de trabajar en el extranjero y durante períodos cortos de tiempo y con la idea posterior de retornar a sus países de origen. Eso no es excusa para que se den las bajas pagas y condiciones pobres de trabajo que en general se dan en la industria del turismo. En concreto, tanto en épocas de verano como en otros períodos cortos a lo largo del año, este tipo de empleos está especialmente "indicado" para estudiantes o inmigrantes provenientes de países del Europa del Este, Africa del Norte, u otros países poco prósperos del entomo mediterráneo y del resto del mundo. Todos estos son puntos de interés siempre que se habla de las relaciones entre Turismo, Migraciones Internacionales y Trabajo. A continuación nos referiremos a ellos más en detenimiento.

Desafortunadamente, no hay muchos datos disponibles sobre el empleo de inmigrantes en el sector turístico evaluando la penetración del empleo en ramas concretas de la industria turística; además, suele tratarse de cifras que varían mucho dependiendo de la escala de la que se trate (local, regional o nacional), de los tipos de trabajos disponibles, de la oferta de mano de obra inmigrante, o de las alternativas del mercado de trabajo.

Por lo general, todos los destinos de turismo masivo (en costa y las grandes ciudades) son polos de atracción para inmigrantes, que tratan de desarrollar negocios en los extremos de la economía turística (economía negra), bien como guías, cambiadores de dinero, o vendedores ambulantes. En los ultimos años ha habido una gran proliferación de africanos en las costas mediterráneas vendiendo productos para los turistas (gafas, cuero, relojes, etc.), negocios todos ellos que les permiten vivir relativamente bien debido a la continua renovación de turistas cada una o dos semanas. También abundan en las costas españolas las colonias de indios vendiendo productos de joyería. Pero quizas lo más generalizado sean los inmigrantes de algún país europeo que inician un negocio turístico en zonas del Mediterráneo relacionado con las costumbres culinarias de su país de origen: es el caso de los numerosos ingleses que establecen un Pub, italianos con pizzerías, etc. Todos estos casos son buenos ejemplos de la interacción entre turismo, migraciones y gustos culinarios, producto de I a conservación de los gustos gastronómicos (el turismo prefiere los platos de su propio país antes que la cocina local). 
Por otra parte, una visita a un restaurante de tapas españolas, o uno griego, en una ciudad noreuropea, siempre trae buenos recuerdos del período de vacaciones que se pasó en ese país. De ahí que la generalización de las vacaciones en los países mediterráneos y la participación de los europeos en el turismo internacional, asegura una cierta clientela en estos países del Norte de Europa siempre que se trata de desarrollar cocinas étnicamente diferentes. En el Reino Unido, en términos de número de restaurantes, el desarrollo de cocina internacional se ha centrado en el gran número de restaurantes italianos, indios, chinos, seguidos de griegos, franceses, españoles, caribenos, mexicanos, libaneses, japoneses, etc. En general, toda esta demanda de cocina extranjera lleva consigo grandes oportunidades empresariales para los diversos grupos étnicos asentados en estos países. En este sentido, ZELINSKY (1985), analizando la relación entre turismo, restaurantes étnicos, y transnacionalización cultural, invita a un estudio de la situación americana, de la misma forma que se $h$ a hecho para Europa.

Pocos países tienen datos disponibles y actualizados sobre los inmigrantes trabajando en turismo pero, por ejemplo, a mediados de la década de los 80, el porcentaje de trabajadores inmigrantes empleados en hoteles y restaurantes sobre el total de trabajadores era de un $38 \%$ en Suiza, un $24 \%$ en Alemania occidental, o un $18 \%$ en Suecia (WILLIAMS \& SHAW, 1991).

Segun otras cifras del informe SOPEMI (1992) tomados de la oficina del Eurostat, de acuerdo con una clasificación llevaba a cabo por la Unión Europea, se muestra la penetración en el mercado de trabajo de trabajadores extranjeros por diferentes ramas de actividad. Desde que el turismo no constituye una única categoría, para su análisis se tienen en cuenta las tres ramas que lo pueden englobar, o que se encuentran más próximas a él (hoteles, cafeterías y comercio; transporte y comunicaciones, y "otros servicios"). Analizando los trabajadores extranjeros de estas tres ramas, se ve que están muy bien representados en países como Suiza y Luxemburgo, algo menos en Holanda y el Reino Unido, y ocupando siuaciones intermedias en Francia ${ }^{3}$, Bélgica y Alemania. Asímismo, se aprecia que el número de trabajadores empleados en las categorías "hoteles, cafeterías y comercio" y "otros servicios", ha crecido rápidamente en la mayoría de los países, y en especial el empleo femenino sobre el masculino (SOPEMI, 1992), lo que habla claramente de la división por géneros de la mano de obra en el sector turístico.

Sobre esas cifras de trabajadores hay que hacer varias puntualizaciones. La penetración de trabajadores extranjeros en las diferentes ramas de actividad, debería

\footnotetext{
3 En el caso de Francia, y para 1991, el 11\% de los trabajadores en las ramas turisticas de la hotelería y la restauración eran trabajadores extranjeros, frente al resto de la economía en donde la dependencia de trabajadores extranjeros era sólo del 6\% (HOLLOWAY, 1993).
} 
distinguirse del porcentaje de extranjeros entre las diversas categorías de empleo. En Bélgica, por ejemplo, es la rama de los hoteles y los restaurantes la que emplea a 1 mayor número de extranjeros, incluso aunque suponga menos del $10 \%$ del total de los empleados en esa rama concreta. Sin embargo, en los países europeos del Mediterráneo caracterizados por una inmigración muy reciente, el dominio del sector turístico en términos de migración de empleo es mayor frente a los países del Norte de Europa aunque no existan muchos datos para corroborar tal afirmación. Por ejemplo, el $73 \%$ de los inmigrantes que tenían en España un permiso de trabajo en 1990 estaban empleados en el sector servicios (incluyendo en él la construccion), frente al 15\% en el sector secundario y el 4\% del primario; en 1994 el porcentaje había subido al $75,8 \%$ en los servicios, con el descenso de los inmigrantes empleados en el secundario al $8,9 \%$, y el aumento de los del primario con el 15,2\% (M.A.S., 1995). Sin embargo, esas cifras representan sólo una parte de todo el total de población extranjera que está trabajando en España, debido al gran número de inmigrantes ilegales y la gran demanda de trabajo estacional y temporal. Ese mismo problema sucede también en Portugal, Italia, Grecia y la costa francesa.

La principal advertencia que podemos hacer sobre los datos "oficiales" de trabajadores extranjeros está relacionada con la "economía negra" o también llamada "informal", ya que mucha población inmigrante trabaja en el sector de una forma encubierta.

Ante la aparición de nuevas formas de entretenimiento y los cambios producidos por la restructuración económica, las firmas turísticas han respondido con la reorganización del proceso laboral, lo que hace que el turismo tenga un significativo impacto en las economías locales, con una importante contribución al empleo local. Hay varias formas con las que las firmas individuales han llevado a cabo la reorganizacion del trabajo, pero casi siempre tales objetivos se han cumplido con la práctica de la economía negra como un modo de reducir de forma directa los costos laborales, además de reducir los precios finales del producto en el mercado -legal-.

La práctica de la economía negra es una característica compartida con otros muchos sectores de la economía, especialmente en países del Sur de Europa donde e1 más tardío desarrollo político y la permanencia de las antiguas estructuras agrarias han conducido a este tipo de organización (MINGIONE, 1991). Sin embargo, lejos de tender a desaparecer, es una práctica cada vez más extendida por todo Europa, tanto en el Norte como en el Sur.

Por otra parte, esta economía informal puede ser vista como una respuesta a la gran competencia del turismo de masas. La naturaleza del turismo de masas -en esencia un producto homogéneo- significa que la competencia se traduce en la reducción de los precios y de los costes de producción. Por eso, la economía informal es una 
respuesta a la reducción de los costes. Un ejemplo importante es Grecia, en donde los hoteles y los apartamentos ilegales aparecían incluso anunciados en la publicidad de los países del Norte de Europa (LEONTIDOU, 1991). De hecho, en todos los países del Sur de Europa donde el turismo de masas está más desarrollado (España, Portugal, Italia, Grecia o algunas partes de Francia), es precisamente donde aparecen las mayores bolsas de este tipo de economía y de trabajadores ilegales. En estos países, la situacion de ilegalidad en que trabajan muchos inmigrantes es un mecanismo que permite reducir ampliamente los costes de mano de obra.

Aunque la información cuantitativa sobre esto es prácticamente inexistente además de poco fiable, VENTURINI (1992) ha estimado que sobre la mitad, o a veces hasta el $80 \%$, de los inmigrantes en Italia estaban empleados de forma ilegal o con alguna anormalidad. En particular, en recientes publicaciones sobre los inmigrantes del "Tercer Mundo" en los países del Sur de Europa hay muchas referencias al empleo de esos inmigrantes desarrollado en hoteles y restaurantes en un contexto de ilegalidad, tanto en centros turísticos fundamentalmente costeros como en grandes ciudades (BEL ADELL, 1989; BONIFAZI, 1994; KING \& RYBACZUK, 1993; MONTANARI \& CORTESE, 1993; IZQUIERDO, 1992).

Muchos de esos trabajos que constituyen la economía negra tienen perfiles muy determinados, en lo que se refiere a género y nacionalidad. Tanto en España como en Italia, las limpiadoras y las camareras de hoteles, sobre todo, proceden por lo general de Filipinas y de países de Latinoamérica. En los hoteles de grandes ciudades como Roma, Londres o París trabaja mayoritariamente personal (sobre todo de porteros y en las cocinas) proveniente de países del "Tercer Mundo" como Somalia, Eritrea, India, Marruecos, etc. Junto a ellos, también los vendedores ambulantes que recorren las calles y playas en zonas de costa son principalmente senegaleses y de otros países africanos.

Entre las razones que se pueden aducir para la persistencia de la economía negra en el sector turístico está la propia naturaleza del turismo, puesto que se trata de una actividad que tiene que proveer sus productos en tiempos y lugares precisos y concretos (WILLIAMS \& MONTANARI, 1995). Esto significa que la demanda de los servicios de turismo es muy desigual y variable a lo largo no sólo del año, sino también de los meses, o del dia ; por lo cuál, dadas las caracterísiticas de los servicios de turismo, que tienen que ser provistos en el momento en que son demandados, los empleos por lo general son de carácter temporal, a tiempo compartido, y funcionalmente muy flexibles, y se llevan a cabo de maneras no tan "regladas" como en otros sectores de la economía.

\footnotetext{
${ }^{4}$ La demanda varía dentro de los diferentes subsectores del turismo, desde las horas puntas en las playas desde mitad de la mañana hasta mitad de la tarde, a los restaurantes en donde es a última hora de la tarde cuando aumenta la demanda, o a partir de las once de la noche para los pubs y discotecas.
} 
En función de la naturaleza del turismo, y tal y como cita URRY (1990), ATKINSON (1984) ha llegado a diferenciar cuatro tipos distintos de flexibilidad en la industria del turismo: flexibilidad numerica, funcional ${ }^{6}$, flexibilidad en "el distanciamiento"7, o la flexibilidad en las pagas ${ }^{8}$. Todas estas estrategias empresariales han empezado a ser adoptadas ante la restructuración económica, y caracterizan a la mayoría de las empresas, no ya sólo en el sector turístico (URRY, 1990).

El empleo, por ejemplo, en la industria hotelera, se caracteriza por la significante presencia de trabajadores a tiempo parcial (SHAW \& WILLIAMS, 1994), de los cuales es sólo posible obtener informacion de unos pocos países. Un estudio de 1 a OCDE (OCDE annual report on tourism) identifica al gran número de mujeres y jóvenes que trabajan en el sector.

Sólo por citar un ejemplo, los trabajadores de las agencias de viaje holandesas ocupan como media tres años en ese tipo de trabajo. Esa rápida movilidad es debida a un conjunto de factores, como las duras condiciones de trabajo que a veces los empleados tienen que soportar, incluyendo largas jornadas, situaciones de elevada presión pero, sobre todo, los relativamente bajos salarios que perciben comparándolos con lo de las demás industrias.

En la mayoría de los países europeos, estos bajos salarios son los que han llevado a que sean las mujeres las que predominen en los puestos considerados de menor categoría profesional (salvo en España, que esto no es siempre del todo cierto, como afirma HOLLOWAY, 1993), y a que también sean los jóvenes los que se sientan atraídos por la facilidad de encontrar trabajos temporales.

En Portugal, por ejemplo, casi el 50\% de todos los empleados son mujeres, mientras que en Grecia es casi el 40\%. En general, los porcentajes son más altos en los países mediterráneos donde, por otra parte, las tasas de ocupación femenina son más bajas (MONTANARI, 1995).

La diferenciación del trabajo por géneros es más patente en la industria del turismo que en las demás. Muchos de esos trabajos son desempeñados por mujeres, y la

\footnotetext{
${ }^{5}$ La flexibilidad numérica permite variar rápidamente el número de trabajadores en función de la demanda existente, así como en función también de los costes de personal (reducción o ampliación de la plantilla).

${ }^{6}$ Se refiere a la disponibilidad que los empleados tienen para desempeñar tareas diferentes en función de las necesidades de cada momento.

${ }^{7}$ Conlleva el desplazamiento de las relaciones internas del empleo por las relaciones comerciales del mercado, con nuevas fórmulas como la subcontratación.

${ }^{8}$ Por la que los empresarios tratan de recompensar económicamente a aquellos trabajadores que tienen una formación diversa, variada, multidisciplinar, etc., o que son multi-funcionales, etc.
} 
mayoría de esas trabajadoras realizan sus trabajos a tiempo parcial asumiendo con ello su condición de trabajadoras a la vez en su hogar y en un lugar de trabajo (WILLIAMS \& MONTANARI, 1995). Esta particular "construcción social", o genderspecific form of behaviour, como también se ha definido (URRY, 1990), les permite a los empleadores reducir claramente los costes laborales pagando menos a sus empleados, de la misma manera que también se practica con los jóvenes y con los inmigrantes.

Relacionado con esta división del trabajo por géneros y la generalización de estas prácticas de trabajo flexibles, los hombres tienden a ocupar los puestos de mayor flexibilidad funcional (pasan por una mayor variedad de trabajos), mientras que las mujeres ocupan la mayoría de los puestos manuales como limpiar, fregar, cocinar, etc. (BAGGULEY, 1990). Estos trabajos desempeñados mayoritariamente por mujeres son los que mejor cumplen la flexibilidad numérica, aunque suelen ser los que peor se adaptan a la funcional. Ello tiene su explicación en que los empleados a tiempo parcial (la mayoría de ellos mujeres), no tienen la oportunidad de prepararse profesionalmente para llegar a ser tan funcionalmente flexibles como lo son los empleados a tiempo completo, y que por lo general son hombres.

A la vez, el turismo es uno de los sectores donde los trabajadores reúnen en conjunto las más bajas cualificaciones, por lo que está muy "abierto" a los inmigrantes. De ahí que buena parte de los empleos del sector turístico, a tiempo parcial, estén desempeñados por mujeres inmigrantes, generalmente de poca cualificación.

Pero las circunstancias varían mucho de unas zonas a otras. En las zonas turísticas del Mediterráneo y en las grandes ciudades europeas, el agotamiento de la oferta de mano de obra ha hecho que la entrada de los inmigrantes a este mercado de trabajo turístico sea grande. En casos como el suizo, los bajos salarios conseguidos en el sector turístico son los responsables, en parte, de los altos porcentajes de inmigrantes trabajando en turismo, y de que la población suiza no participe de esta industria debido a los bajos salarios y a la estacionalidad que supone; sólo un tercio de todos los trabajadores del sector turístico en Suiza tienen trabajos permanentes (GILG, 1991). Sin embargo, en las zonas rurales de Europa, el turismo de pequeña escala se basa mucho más en la mano de obra local como las mujeres y los trabajadores a tiempo parcial compaginando las tareas ligadas al turismo con las agrícolas (CLOUT, 1984). Esto hace que el empleo de los trabajadores inmigrantes tenga otros efectos en el sector turístico como hacer caer los salarios, hacer los trabajos poco atractivos para la población local, aunque a la vez, también hace a la industria competitiva y rentable. Por eso la competitividad de los precios es importante en el turismo de masas, donde la falta de productos diferenciados hace que la competencia sea alta para la reducción de los precios. 


\section{DESAROLLO DEL TURISMO Y MIGRACIONES DE RETORNO}

Aunque la migración de trabajo internacional ha generado el asentamiento de numerosas comunidades étnicas en el Norte y Oeste de Europa particularmente como resultado de las fuertes olas migratorias de los años 50 y 60 desde zonas del Mediterráneo, las oleadas contrarias, de retorno a sus países de origen, ha sido también un fenómeno que para el sector turístico ha tenido mucha importancia. Por naturaleza, la mayoría de aquellos emigrados han vuelto a sus países de origen, motivados en algunos casos, por las políticas de retorno que emprendieron algunos países de acogida. Tales políticas tuvieron su auge en las décadas de los años 70 y 80 , una vez que entró en declive el mismo sistema productivo Fordista que antes los había hecho emigrar. Francia durante los años 70, o Alemania en los 80, fueron los principales países "expulsores", mientras que en los países de origen de esos emigrantes se iban creando las condiciones para la rápida integración de todos los retornados. Todo ello se vio favorecido por determinados factores del ciclo de la vida: muchos migrantes que habían salido de sus países en edad juvenil, tras varios años de trabajo en el extranjero, sentían la necesidad del retorno, y de afrontar la última parte de sus vidas en sus países de origen.

De esta forma, muchos países de Europa del Sur que habían sido tradicionalmente emigratorios, desde finales de los años 70 empezaron a recibir población retornada, y a convertirse en receptores de fuerza de trabajo: es el caso de Espãna, Portugal, Irlanda o Grecia.

Aunque algunos de esos retornados no han contribuído en gran manera al desarrollo de interesantes experiencias económicas, muchos de ellos volvieron con experiencias y capital acumulados además de cierta preparación profesional y conocimiento de un idioma al menos diferente al suyo. Con todo ello, se convertían en empresarios "potenciales" para el desarrollo de pequeñas empresas turísticas.

La evaluación del impacto de las migraciones de retorno en el desarrollo del turismo está muy condicionada por la gran carencia de información sobre el tema. De ahí que todas las publicaciones existentes estén referidas a estudios-caso llevados a cabo en zonas concretas de países europeos del Sur. Si en Portugal y en Italia es donde más experiencias de este tipo se han estudiado referidas al desarrollo de empresas turísticas (LEWIS \& WILLIAMS, 1986; REIS \& GIL, 1986, o TOOK, 1986), también Grecia (MANGANARA, 1977), Turquía (TOEPFER, 1985) o la antigua Yugoslavia (BAUCIC, 1972 y BENNETT, 1979) han sido objeto de atención de los investigadores. Pero por lo general, todos estos estudios se han centrado en el desarrollo de actividades turísticas, salvo contadas excepciones en que también se ha prestado atención a la puesta en marcha de iniciativas agrarias por parte de los retornados 
(BLACK, 1993). ARDITTIS (1988) se refiere en general a estos retornados como personas que reúnen tres características principales, relacionadas con el empleo:

1) La primera es que no desean volver e incorporarse a las tareas agrícolas que un día abandonaron. La mayoría de ellos opinan que las tareas del campo están mal pagadas y gozan de baja consideración, por lo que casi todos buscan algo mejor. A menudo este mejor estatus es encontrado en el sector terciario.

2) Este ciclo geográfico de las migraciones y del retorno implica primero un desplazamiento de personas empleadas en el sector primario al secundario en el momento de la emigración-, para después regresar al país de origen y trabajar en el terciario. Eso sí, si bien muy pocos de esos empleos en el sector terciario se desarrollan en el sector público, la mayoría tienen que ver con experiencias particulares de pequeñas empresas de servicios, dominando las turísticas entre ellas.

3) La tercera tendencia señalada por Ardittis es el incremento del auto-empleo entre las experiencias empresariales desarrolladas tras el retorno. $Y$ curiosamente, este auto-empleo encuentra el mayor número de oportunidades en el sector turístico, donde es relativamente más sencillo hacerse con una empresa, que en otros donde el requirimiento de cualificación podría ser mayor. No obstante, las experiencias empresariales en el sector servicios se han desarrollado de diversas formas, de unos lugares a otros.

Si a lo poco atractivo que resulta el sector primario se le añade el escaso desarrollo industrial en muchas de las zonas de retorno, eso hace que la mayoría de los pequeños proyectos empresariales desarrollados por los retornados giren en torno a 1 turismo.

En ausencia de cualquier dato estadístico sobre el tema, a continuación presentamos tres casos estudiados en zonas del Mediterráneo, en los que se intenta presentar y explicar los procesos desarrollados:

El primero de los casos fue estudiado por MENDONSA (1982) y trata de medir el impacto de la migración de retorno en la pequeña ciudad pesquera de Nazaré, a 60 $\mathrm{km}$. al Norte de Lisboa. Comparando los retornados del extranjero con los no emigrados y con la población que había emigrado al resto de Portugal, Mendonsa encontró que los retornados de otro país formaban un colectivo bien asentado y con gran éxito en sus empresas y negocios. La explicación puede estar en que en su etapa en el extranjero estos emigrantes habian ahorrado suficiente capital para invertirlo a su regreso en un negocio de este tipo (por lo general pequeños hoteles, cafés, restaurantes y otros 
pequeños establecimientos comerciales). En muchos casos los ahorros no proceden solamente de lo conseguido en el extranjero, sino también del rendimiento que se $h$ a obtenido de la vivienda que tenían antes de salir de Portugal, gracias a su alquiler a visitantes. Según Mendonsa, el $78 \%$ de los emigrantes retornados alquiló alguna vivienda o propiedad a los turistas en su período de ausencia, comparado con el $41 \%$ de los no emigrantes. Además del hecho de que los emigrantes fueron elevando su posición socioeconómica desde una más baja al principio que otros grupos, después del retorno se les puede hallar en una situación mejor y más estable. Comparando los ingresos de los retornados con los que no habían emigrado, los de los primeros eran sensiblemente superiores a los segundos: 196 dólares frente a 106 dólares (a finales de la década de los 80). La diferencia, por un lado, se debe a los ingresos ahorrados durante todo el tiempo en el extranjero, y por otro lado a los beneficios obtenidos por las propiedades poseídas durante todo ese tiempo que estuvieron fuera. Este es un buen ejemplo para demostrar la complementariedad y la simbiosis entre el desarrollo turístico y la migración de retorno: cada uno de los dos facilita y fomenta al otro.

El segundo caso, con bastantes similaridades al primero, se basa en un estudio llevado a cabo por King et al. (1984) en la ciudad italiana de Amantea, en la región de Calabria al Sur de Italia. Los autores entrevistaron a un total de 79 retornados y encontraron que un grupo numeroso de ellos (el 38\%) habían regresado a su país de origen para crear, o encontrar un trabajo, relacionado con el sector servicios (en concreto con el desarrollo turístico, de forma directa o indirecta). Entre el conjunto de empresas desarrolladas encontraron gran variedad, destacando las que se ligaban más directamente con el turismo como los hoteles, alquiler de apartamentos, pequeños comercios, bares, garages, etc., estando todas ellas condicionadas a la estación veraniega de mayor afluencia turística. Por nacionalidades, los retornados más activos fueron los que habían estado en Venezuela (por otra parte, el destino preferido para la mayoría de los emigrados de la ciudad), donde habían acumulado experiencias de trabajar en el sector servicios antes de regresar. Un recuento del total de infraestructuras turísticas en la ciudad (14 hoteles, 23 bares, 12 restaurantes, 6 pizzerías, 6 discotecas y alrededor de 6.000 camas en casas privadas y apartamentos para alquiler) reveló que la mayoría habían sido creados con capital traído por los retornados. Por otra parte, sin tener en cuenta las 6.000 camas privadas, todas estas empresas generaron alrededor de 310 puestos de trabajo, lo cual se considera un impacto importante en una pequeña ciudad de ese tamaño.

El tercer caso presentado tiene que ver con un estudio llevado a cabo en 1 a antigua Yugoslavia. A finales de los años 60 se empezó a detectar que zonas de interior como Dalmacia y el Oeste de Herzegovina empezaban a estar saturadas de establecimientos turísticos (cafes, pubs, restaurantes), mientras que las zonas costeras íban atrayendo la atención de los primeros retornados que abrían pequeños hoteles y 
habitaciones para alquilar (fundamentalmente en la costa dálmata) (BAUCIC, 1972).

Un estudio también de la isla croata de Brac reveló la gran importancia de la migración de retorno y del capital ahorrado en el extranjero para el desarrollo turístico de la isla (BENNETT, 1979). Los retornados invirtieron fundamentalmente en restaurantes, casas de huéspedes, y en general en todo lo relacionado con el turismo, por lo que los efectos multiplicadores de tales actividades no se hicieron esperar en el resto de la economía local (en la construcción, el comercio, en la alimentación lo cual beneficiaba directamente a los agricultores, etc.), contribuyendo tanto los turistas como los locales al relanzamiento de la economía local. En esta situación se produjo el choque generacional entre la nueva ola de retornados, relativamente jóvenes, que estaban asumiendo los papeles de nuevos empresarios en el desarrollo de empresas turísticas, y sus padres, que permanecían ligados a los tradicionales trabajos agrarios.

Finalmente, podemos citar otro modo por el que la migración de retorno internacional se liga al desarrollo del turismo. Como CAVACO señala (1993) en su estudio sobre los retornados a Portugal, el retorno cada verano de los emigrados a sus pueblos y pequeñas ciudades de origen, puede ser considerado como una migración turística. Ese mes en que los emigrantes pasan en sus lugares de origen, según Cavaco puede ser considerado como una forma embrionaria de "turismo rural", ya que contribuyen a la creación de una demanda veraniega y al desarrollo del turismo y de la economía local en las diferentes variedades de agroturismo o de práctica del camping. Durante ese tiempo, las familias de los emigrantes, acostumbradas a tratar con personas extranjeras y en una lengua diferente, van desarrollando una vocación lucrativa desarrollando este tipo de "turismo rural" destinado a los extranjeros, y que ha sido tan exitoso en regiones como la Toscana o Dordoña. Por supuesto que no todas las regiones, que en su día fueron de emigración, cuentan con las mismas riquezas paisajísticas, culturales, unidas a las climáticas, como Portugal, para el desarrollo de ese turismo, por lo que, en principio, su desarrollo está espacialmente bastante restringido.

Todos estos casos vistos no son más que algunos ejemplos de un fenómeno que h a sido mucho más numeroso, fundamentalmente en zonas costeras de países del Mediterráneo. Tal proliferación de pequeños establecimientos de servicios ligados a 1 turismo por parte de los ex-emigrantes ha sido muchas veces una de las causas de la modificación del paisaje y de estos pequeños núcleos urbanos. Pero como dijimos, no son más que pequeños ejemplos tomados de casos particulares, realizados hace ya algunos años, en el momento de mayor auge del fenómeno del retorno de esos emigrantes a sus lugares de origen. En la medida en que tal fenómeno entró en declive, el número de estudios ha ido también declinando, por lo que en estos momentos cabría desarrollar otro tipo de estudios centrados en las actividades que, con el tiempo, siguen 
desarrollando los retornados. $\mathrm{O}$, por contra, determinar el papel que el turismo $\mathrm{h}$ a tenido en la redistribución de esos retornados, en el sentido de que muchos de ellos, que salieron de zonas eminentemente rurales, ya no regresan a ellas sino a núcleos más grandes, y turísticos casi siempre, con el fin de sacar máximo provecho a sus inversiones turísticas.

\section{CONCLUSIONES}

En esta exposición teórica sobre la internacionalización del turismo en el ámbito europeo y su conexión con el tema de las corrientes migratorias hemos intentado un acercamiento al tema del mercado de trabajo, donde las necesidades del turismo como industria se relacionan estrechamente con la oferta de trabajo flexible. Eso hace de los trabajos en el sector turístico poco atractivos para las poblaciones locales, que desean trabajos más permanentes, salvo en regiones pobres donde el desempleo es elevado o donde la población local es capaz de compaginar el trabajo estacional del turismo con las tradicionales actividades agrarias (o también de la construcción). Los inmigrantes, y particularmente los estudiantes que están dispuestos a trabajar durante sus vacaciones, son el tipo de personas más idóneas para los patronos de las empresas turísticas ya que se adaptan perfectamente a las condiciones de temporalidad que requieren los trabajos, a cambio de bajos salarios y sin cobertura social de ningún tipo. De ahí que casi todas estas prácticas se desarrollen a la sombra, y en el contexto de la economía negra. O bien trabajando "ilegalmente" para un patrón, o bien de forma autónoma aprovechando la gran demanda turística y vendiendo productos para los turistas.

La relación entre migraciones internacionales y el turismo de masas es prácticamente recíproca. Por un lado el turismo de masas (y/o el urbano) genera migraciones internacionales, y por otro, determinadas corrientes migratorias se nutren básicamente de inmigrantes que desempeñan papeles importantes en el mercado de trabajo turístico, bien como empleados, o como propietarios de empresas. De esta manera, la existencia de una mano de obra barata en el sector puede contribuir a la perpetuidad de los bajos costes y al descenso de los precios finales que el turista paga por la adquisición de los servicios, contribuyendo todo ello al mantenimiento de la ya extendida economía negra, y tan difícil, por otra parte, de erradicar.

Pero otras relaciones se vislumbran entre ambos conceptos. El impacto económico y cultural del turismo en una región puede provocar la emigración de los jóvenes, inducidos por la modas que el turismo siempre acarrea, hasta el punto de sentirse "incitados" a la emigración. 
Aparte de eso, las experiencias que en cualquier país europeo se pueden ver sobre la proliferación de restaurantes de cocina internacional demuestran que el producto turismo-migraciones desemboca en multitud de experiencias empresariales. Y unido a ellas, están también las emprendidas por antiguos emigrantes una vez que regresan a su país de origen, aprovechando la coyuntura de que, por lo general, son zonas que en el tiempo de ausencia se han ido desarrollando turísticamente.

\section{BIBLIOGRAFIA}

ARDITTIS, S. (1988): "Migration de Retour en Europe du Sud", Migration Working Paper, 39, Ed. International Labour Office, Geneva.

ATKINSON, J. (1984): Flexibility, Uncertainly and Manpower 1, Institute of Manpower Studies, Report 89, Ed. University of Sussex, Falmer.

BAUCIC, I. (1972): "The Effects of Emigration from Yugoslavia and the Problems of Returning Migrant Workers". European Demographic Monographs, 2, Ed. Nijhoff, Le Hague.

BEL, ADELL, C. (1989): "Extranjeros en España". Papeles de Geografía, 15, 21-35.

BENNETT, B. C. (1979): "Migration and rural community viability in central Dalmatia (Croatia), Yugoslavia. Papers in Anthropology, 20 (1), 75-83.

BLACK, R. (1993): Migration, Return, and Agricultural Development in the Serra do Alvao, Northern Portugal". Economic Development and Cultural Change, 41 (3), 563-585.

BONIFACE, B. \& COOPER, C. (1994): The Geography of Travel and Tourism. Ed. ButterworthHeinemann, Oxford.

BONIFAZI, C. (1994): "Size and characteristics of foreign immigration in Italy". Labour, 81 (1), 173-190.

CASTLES, S. \& KOSACK, G. (1973): Immigrant Workers and Class Structure in Western Europe. Ed. Oxford University Press, London.

CAVACO, C. (1993): "A place in the sun: return migration and rural change in Portugal". En, R. King (Ed.): Mass Migrations in Europe: the Legacy and the Future. 174-191, Belhaven, London.

CLOUT, H. D. (1984): A Rural Policy for the EEC?. Ed. Methuen, London.

COHEN, R. (1987): The New Helots: Migrants in the International Division of Labour. Ed. Aldershot, Avebury.

COOKE, P. (Ed.) (1989): Localities. Ed. Unwin Hyman, London.

DICKEN, P. (1992): Global Shift: The Internationalization of Economic Activity. Ed. Paul Chapman, London. 
FIELDING, A. J. (1993): "Mass migration and economic restructuring, En, R. King (Ed.): Mass Migrations in Europe: the Legacy and the Future. 7-18, Belhaven, London.

FINDLAY, A. (1996): Extra-Union Migration: The South-North Perspective". En, P. Rees, J. Stillwell, A. Convey \& M. Kupiszewski (Eds.): Population Migration in the European Union. 39-50, John Wiley \& Sons, Chichester.

FORTE, C. (1986): Forte: the Autobiography of Charles Forte. Ed. Sidgwick \& Jackson, London.

GILG, A. W. (1991): "Switzerland: structural change within stability." En, A.M. Williams \& G. Shaw (Eds.): Tourism and Economic Development: Western European Perspectives. 130-152, Belhaven, London.

GOLINI, A., BONIFAZI, C. \& RIGHI, A. (1993): “A general framework for the European migration system in the 1990s"s. En, R. King (Ed.): The New Geography of European Migrations. 67-82, Belhaven, London.

HOLLOWAY, C. (1993): "Labour, Vocational Education and Training". En, W. Pompl \& P. Lavely (Eds.): Tourism in Europe. Structures and Developments. 99-117, Cab Int., Cambridge.

HUGHES, C. (1991): Lime, Lemon and Sarsaparilla: the Italian Community in South Wales 18811945, Ed. Seren Books, Bridgend.

IZQUIERDO, A. (1992): La inmigración en España, 1980-1990. Min. de Trabajo y Seguridad Social, Madrid.

KING, R., MORTIMER, J. \& STRACHAN, A. J. (1984): “Return migration and tertiary development: a Calabrian case-study." Anthropological Quarterly, 57 (3), 112-124.

---- \& RYBACZUK, K. (1993): "Southern Europe and the international division of labour: from emigration to immigration". En, R. King (Ed.): The New Geography of European Migrations. 175206, Belhaven, London.

---- STRACHAN, A. \& MORTIMER, J. (1986): "Gastarbeiter go home: Return migration and economic change in the italian Mezzogiorno". En, R. King (Ed.): Return Migration and Regional Econonic Problems. 38-68. Croom Helm, London.

LEONTIDOU, L. (1991): "Greece: prospects and contradictions of tourism in the 1980s". En, A. M. Williams \& G. Shaw (Eds.): Tourism and Economic Development: Western European Perspectives. 84-106, Belhaven, London.

LEWIS, J. \& WILLIAMS, A. (1986): "The Economic Impact of return migration in central Portugal" En, R. King (Eds.): Return Migration and Regional Economic Problems. 100-128, Croom Helm, London.

LOWYCK, E. \& WANHILL, S. (1992): “Regional development and tourism within the European Community." En, C. Cooper \& A. Lockwood (Eds.): Progress in Tourism, Recreation and Hospitality Management, 4, Belhaven, London.

MANGANARA, J. (1977): "Some social aspects of the return movement of Greek migrant workers from West Germany to rural Greece". The Greek Review Social Research. 29, 65-75. 
M.A.S. (MINISTERIO DE ASUNTOS SOCIALES) (1995): Anuario de Migraciones 1995. Ed. Dir. Gral. de Migraciones, Madrid.

MENDONSA, E. (1982): "Benefits of migration as a personal strategy in Nazare, Portugal." International Migration Review, 16 (3), 635-645.

MINGIONE, E. (1991): Fragmented Societes. Ed. Blackwell, Oxford.

MONTANARI, A. (1995): "The Mediterranean Region: Europe's Summer Leisure Space". En, A. Montanari \& A. M.Williams (Eds.): European Tourism. Regions, Spaces and Restructuring. 4165, John Wiley \& Sons, Sussex.

MONTANARI, A. \& CORTESE, A. (1993): "South to North migration in a Mediterranean perspective". En, R. King (Ed.): Mass Migrations in Europe: the Legacy and the Future. 212-233, Belhaven, London.

PIORE, M. J. (1979): Birds of Passage: Migrant Labour in Industrial Societes. Cambridge University Press. London.

REIS, M. \& GIL NAVE, J. (1986): “Emigrating peasants and returning emigrants. Emigration with return in a portuguese village". Sociologia Ruralis, 2b, 20-35.

RHOADES, R. E. (1978): "Intra-European Return Migration and Rural Development: Lessons from the Spanish Case". Human Organization. 37, 136-147.

SALT, J.; SINGLETON, A. \& HOGARTH, J. (1994): Europe's International Migrants: Data Sources, Patterns and Trends. Ed. HMSO, London.

SHAW, G. \& WILLIAMS, A. M. (1994): Critical Issues in Tourism: A Geographical Perspective. Ed. Basil Blackwell, Oxford.

SOPEMI (1992): Trends in International Migration. Ed. OECD, Paris.

TOEPFER, H. (1985): "The economic impact of returned emigrants in Trabzon, Turkey". En, F. Hudson \& J.R. Lewis (Eds.): Uneven Development in Southern Europe. 76-100, Methuen, London.

TOOK, L." (1986): "Land tenure, return migration and rural change in the italian province of Chieti. En, R. King (Ed.): Return Migration and Regional Economic Problems. 79-99, Croom Helm. London.

URRY, J. (1990): The Tourist Gaze. Leisure and Travel in Contemporary Societies. SAGE, London.

VALENZUELA, M. (1988): "Spain: the phenomenon of mass tourism." En, A. M. Williams \& G. Shaw (Eds.): Tourism and Economic Development: Western European Perspectives. 39-57, Belhaven, London.

VENTURINI, M. (1992): "Immigration et marché du travail en Italie: données récentes". Revule Européenne des Migrations Internationales. 8 Suppl, 145-161.

WILLIAMS, A. M. \& MONTANARI, A. (1995): "Introduction: Tourism and Economic Restructuring in Europe". En, A. Montanari \& A. M. Williams (Eds.): European Tourism. Regions, Spaces and Restructuring. 1-15, John Wiley \& Sons. Sussex. 
WILLIAMS, A. M. \& SHAW, G. (1991): "Western European tourism in perspective". En, A. M. WILLIAMS \& G. Shaw (Eds.): Tourism and Economic Development: Western European Perspectives. 31-39, Belhaven, London.

WTO (1986): Economic Revietu of World Tourism. Ed. O.M.T., Madrid.

ZELINSKY, W. (1985): "The roving palate: North America's ethnic restaurant cuisines". Geoforum, $16(1), 51-72$. 